\title{
Technological Schemes at the Transverse Mining System of the Open Pit Mine's Bottom Layer
}

\author{
Eugene Makridin ${ }^{1,2,}$, Martin $\mathrm{Kapko}^{3}$, and Martin $\mathrm{Straka}^{3}$ \\ ${ }^{1}$ JSC SUEK-Kuzbass, 1 Vasil'eva st., 653053 Leninsk-Kuznetsky, Russian Federation \\ ${ }^{2}$ T.F. Gorbachev Kuzbass State Technical University, 28 Vesennyaya st., 650000 Kemerovo, Russia \\ ${ }^{3}$ Technical University in Kosice, Institute of Earth Resources, Faculty of Mining, Ecology, Process \\ Control and Geotechnologies, Park Komenského 19, 042000 Košice, Slovakia
}

\begin{abstract}
At the quarry fields with inclined and steep occurrence of complex structural coal seams formations of Kuzbass, it is preferable to use transverse mining systems. In this case, transport costs are significantly reduced and alienation of land areas for external dumps is reduced too. It is also possible to apply an effective transportless technology of stripping operations. Absence at this technology of expensive and ecologically dangerous quarry dump trucks allows extracting coal with smaller expenses, makes it more competitive in the domestic and foreign coal market. However, for the design of such technology in the conditions of transverse direction of the mining front, at present, theoretical studies of issues related to the justification of its parameters and the choice of mining equipment are insufficient. A wide range of coal bed formation conditions, a wide range of standard sizes of draglines used in the transportless technology, as well as various values of the depth of mining predetermine the multi-variant solution of the above problems. In this case, the formation of possible variants of mining operations with the use of certain models of excavators for their subsequent evaluation by any criterion is in itself a rather complicated task.
\end{abstract}

\section{Introduction}

At present, there are no publications in the scientific literature on the technological schemes of the transportless bottom layer excavation and justification of its main parameters. The general view of the continuous transverse mining system with excavation of the bottom layer by the transportless technology is shown in Fig. 1. The following designations are accepted on the scheme: $H_{t r}$ - height of a transportless layer (bench), m; $A, A_{t}$ - width of a drilling-and-blasting stope on a transportless and transport benches respectively, $\mathrm{m} ; \alpha-$ angle of a slope of transport and transportless overburden benches, degrees; $\alpha \mathrm{o}$ - angle of a slope of a dump, degrees; $W$ - the width of the working site of the transport bench, $\mathrm{m} ; \mathrm{W}_{\mathrm{s}}-$ the width of shotpile, $\mathrm{m} ; H_{t}$ - the height of the transport bench, $\mathrm{m} ; H_{d}$ - the height of the

\footnotetext{
*Corresponding author: makridin suek@mail.ru
} 
internal dump, m; $a$ - the shortest distance from the axis of the dragline working path to the place of installation of a dump truck for loading, $\mathrm{m} ; R_{\text {dig }}$ and $R_{\text {dump }}$ - respectively, the radius of digging and dumping of the dragline, $\mathrm{m}$.

The operating sequence on the combined transport and transportless technology $[8,9$, $15,22]$ is as follows. The upper transport bench is worked out by a rope shovel with the lower loading of overburden and coal into dump trucks. Rock and coal are transported through a temporary trench located on a working bench. This scheme ensures lower cost of coal produced [23].
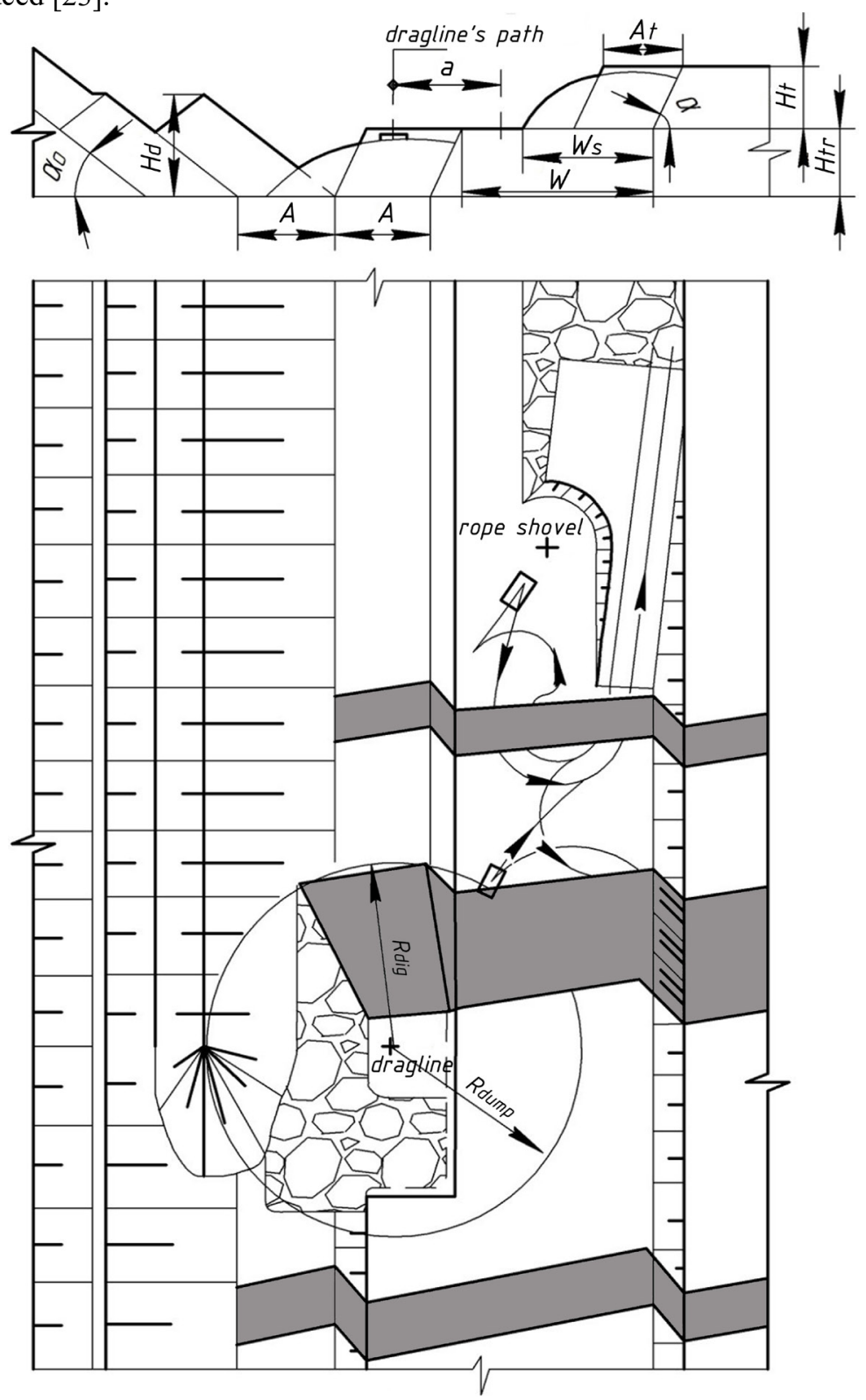

Fig. 1. General view of transverse mining system.

The bottom layer is worked out on the transportless technology using dragline. According to this scheme, the bench is developed in one layer. Overburden rock is placed 
in a single-tier dump, and coal is loaded into dump trucks located on the working site of the bench $[1,4-6,25]$.

The access of dump trucks for loading is made on a trench (dead-end) scheme of turning.

\section{Materials \& Methods}

The dragline face should be behind of the shovel face by the distance that is necessary for the safe operation of two excavators and be opposite in the direction of moving of the transport bench' face.

Mining and geological conditions of the Kuzbass coal deposits suitable for mining by transverse mining systems are shown in Fig. 2. In these deposits, seams occurrence varies over a wide range from 15 to $75^{\circ}$ or more, the thickness of the working seams is $2-20 \mathrm{~m}$, the number of workable seams is 3-6. According to the bedding structures and the calculation of the boundary stripping ratio for transverse mining systems, the depth of mining of such deposits will be 120-280 m. Opening-up of quarry fields can be carried out by internal trenches created on the mining flank of the quarry [2, 3, 23]. The maximum width of the quarry bottom during mining of a formation of 3-5 seams is more than $800 \mathrm{~m}$; the minimum is more than $200 \mathrm{~m}$. With such a relatively short length of the transportless layer and, consequently, excavator stopes, draglines of small and medium power types (ESH 6.5.45, ESH 13.50, ESH 14.50, ESH 10.70A, ESH 11.70) can practically be used.

The use of draglines for transportless technology in these conditions has its advantages and disadvantages [7, 17, 21].

Some of the advantages are lower expenses in comparison with using of excavatorautomobile-dump complexes, simpler organization of mining works [12, 14, 16-20].

At the same time, the production of winning operations by dragline is complicated, as structurally its working equipment does not fully meet the requirements of this type of excavation. The alternation of stripping and winning operations limits the excavator's maneuverability, which consists in the possibility of its movement in a transverse direction. It is known that the displacement of the axis of the dragline path has a significant impact on the full use of the working parameters of the excavator (digging radius etc.).

The main parameters of the transportless layer are: height $\left(H_{t}\right)$, width of the drilling and blasting stope $(A)$ and minimum length of the quarry bottom $\left(L_{b}\right)$. The height of the layer is determined by the design of the excavation scheme, the model of the dragline used, the stability of the internal dump and the strength limit of the overburden.

To determine the layer height, a number of excavation schemes have been developed. At their development it is considered, that maneuverability of a dragline is limited on sites of winning operations.

The following restrictions have been adopted on the condition of stability of the internal dump $[10,11,13]$ : the height of a single-tier dump can reach 30-40 $\mathrm{m}$ at the bottom of the dumps, composed of weak rocks (coal clays, mudstones, weak siltstones), which is typical for the Central Kuzbass deposits; when the multi-tier internal dump spoiling at the same bottom, the height of the first tier (extended bench) should not be more than 20-25 m with a natural slope angle of $35-37^{\circ}$, and the resulting angle of slope should not exceed $26-27^{\circ}$ [3]. With a solid bottom (sandstone, dense siltstones) the height of single-tier dump can't reach 40-60 $\mathrm{m}$ and more, when dumping multi-tier dumps the height of the first tier (extended bench) should not be more than $30-40 \mathrm{~m}$ with a natural slope angle of $35-37^{\circ}$, and the resulting angle of slope should not exceed $27-31^{\circ}$. 

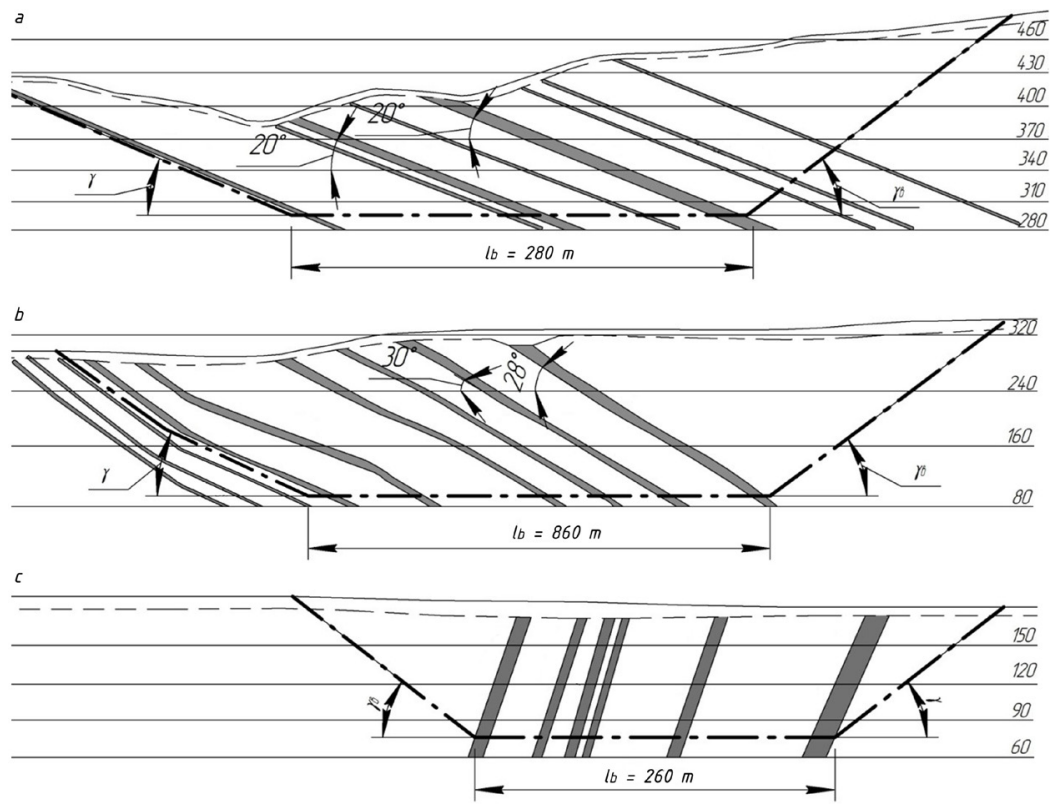

Fig. 2. Typical geological cross-sections of deposits suitable for using transverse mining systems: a south Kuzbass, b, c - eastern part and western part of central Kuzbass, respectively.

\section{Results and Discussion}

Since the values of stable dump heights are significant, the limiting parameters of the internal dump will be equal to the working parameters of the dragline: the digging radius $\left(R_{d i g}\right)$, the dumping radius $\left(R_{\text {dump }}\right)$ and the dumping height $\left(H_{\text {dump }}\right)$. The width of drilling and blasting stopes is applied according to the data of draglines' working practice and the recommendation of "Typical technological schemes of mining operations at coal open pit mines" [24]. For excavators with $45-50 \mathrm{~m}$ boom length the width of such stope is $20-25 \mathrm{~m}$, for draglines with $70 \mathrm{~m}$ boom length it is $30-35 \mathrm{~m}$.

The influence of the rock strength on the height of the transportless bench is connected with the geometry of the stope profile. During excavation, weak rocks of the III category by difficulty of excavation require shock blasting of the rock mass with specific consumption of explosive equal to $0.25-0.35 \mathrm{~kg} / \mathrm{m}^{3}$ to increase the cracking of the mass. In this case, after the explosion the initial contour of the bench is almost unchanged, which determines the location of the dragline. Overburden benches formed by stronger rocks of III-IV category after the explosion with specific consumption of explosive equal to $0.5-0.8 \mathrm{~kg} / \mathrm{m}^{3}$ lose their original shape, and the break-up of the rock forms a curved surface. In this case, the geometry of the breakup determines the location of the dragline relative to the design contour of the internal dump.

To determine the height of the transportless layer, taking into account the abovementioned features and limitations, two groups of excavating schemes have been developed for the mining of the transportless layer with one bench (Fig. 3a, b, c). 


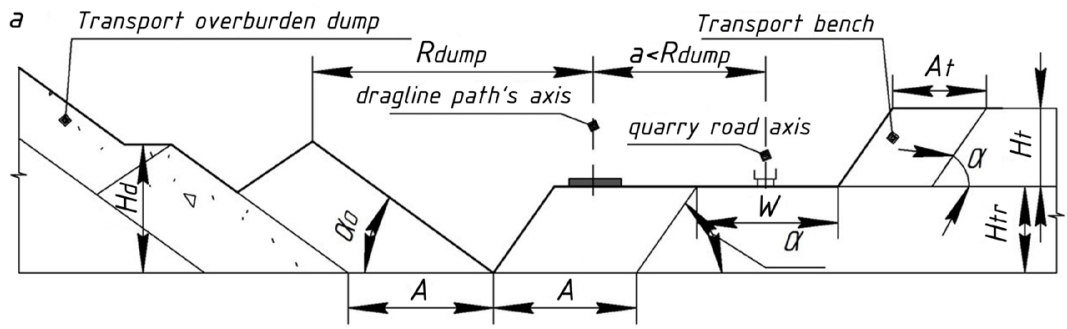

$b$
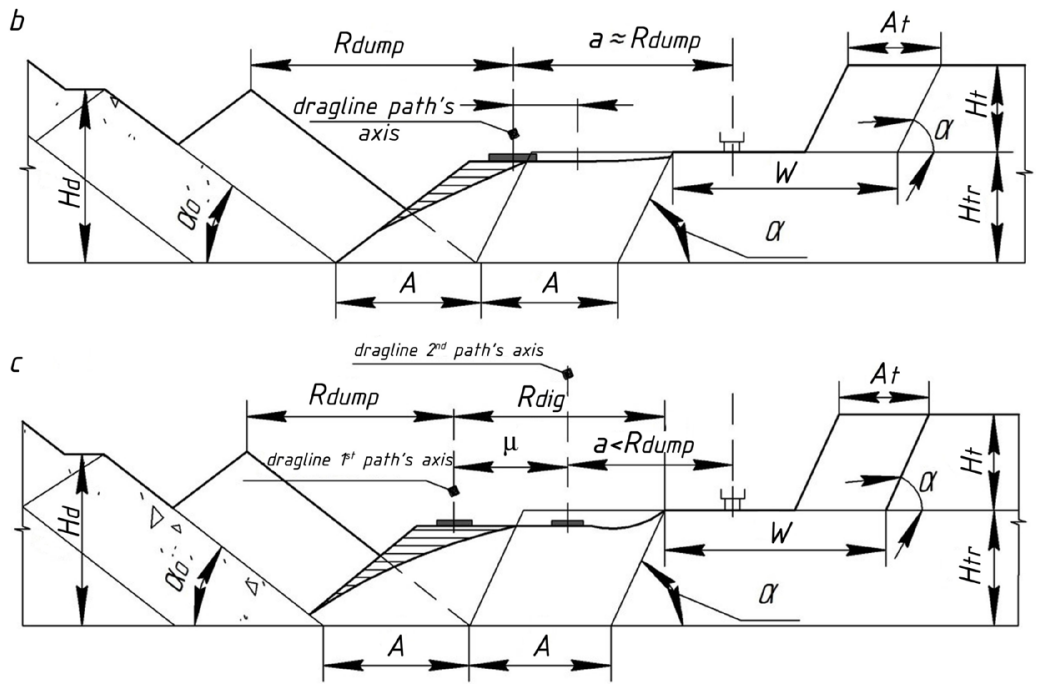

Fig. 3. Excavation schemes for the mining of the transportless layer in one bench: a - for rocks of IIIII Id excavation difficulty category; $b, c-$ for rocks of IV th excavation difficulty category: $b$ - with a linear stroke (axis) of the excavator at the mining front, $\mathrm{c}$ - with the excavator shifted towards the dump.

Fig. 3a illustrates the profile of a simple excavation scheme for rocks of II-III category. Dragline is placed on the roof of the overburden bench. The excavator moving the overburden into a single-tier dump with the maximum use of the dumping radius as the work is done. When coal seams are mined off, the coal is transported directly to the coal storage located at the working site of the transport bench. The distance between the excavator's working stroke axis and the position of the coal storage during loading (parameter $a$ ) may be less or equal to the dumping radius $\left(a \leq R_{\text {dump }}\right)$.

Fig. $3 b$ illustrates the profile of the excavator scheme for strong rocks of III ${ }^{\text {rd }}$ or IV $^{\text {th }}$ category, which is characterized by a linear stroke of the excavator at the mining front. Both stripping and winning operations are performed in this process. The dragline is placed on the shotpile with a shift towards the dump. The maximum shift (displacement) is limited by the condition of coal loading during the winning operations, therefore the distance between the axis of the dragline's working stroke and the place of the dump truck installation during loading is maximum and approximately equal to the unloading radius $\left(a \approx R_{\text {dump }}\right)$.

Fig. 3c illustrates the scheme of excavation characterized by alternating displacement of the working stroke axis in the profile during stripping and winning operations. In order to maximize the use of digging and dumping radii, during stripping operations, the axis of the $1^{\text {st }}$ working stroke is shifted towards the dump, for which an intermediate spoil for the route of the working stroke is created. Under this condition, the height of the transportless layer is 
determined. For winning operations, the dragline is shifted to the position of the $2^{\text {nd }}$ working stroke so that it is possible to excavate coal with minimum losses and load it into the dump truck $\left(a \leq R_{d u m p}\right)$.

\section{Conclusions}

1. At transverse mining systems of inclined and steep coal deposits on the transportless technology depending on mining and geological conditions of the deposit it is possible to develop bottom layer of the quarry with height $10-38 \mathrm{~m}$. This may amount to $15-30 \%$ of the volume of the entire coal-and-rock mass of the quarry field.

2. For the mining of near-bottom transportless layer due to its relatively small length of 250-850 $\mathrm{m}$ the models of draglines of small and medium power types (ESH 6.5.45, ESH 13.50, ESH 14.50, ESH 10.70A, ESH 11.70) can be used.

3. The minimum width of the quarry field at which the transportless technology can be used, is $220-250 \mathrm{~m}$, which is determined by the length of the temporary trench, created on the working flank for opening-up the transport benches and meets the conditions of the Kuzbass perspective coal deposits.

\section{References}

1. E.A. Tyuleneva, Yu.V. Lesin, Ya.O. Litvin, Journal of Mining and Geotechnical Engineering, 1(4), 35 (2019). DOI: 10.26730/2618-7434-2019-1-35-49

2. A.V. Strelnikov, Journal of Mining and Geotechnical Engineering, 3(6), 4 (2019). DOI: $10.26730 / 2618-7434-2019-3-4-20$

3. A.V. Strelnikov, Journal of Mining and Geotechnical Engineering, 4(7), 4 (2019). DOI: $10.26730 / 2618-7434-2019-4-4-29$

4. D.M. Dubinkin, V.Yu. Sadovets, G.O. Kotiev, A.V. Kartashov, Journal of Mining and Geotechnical Engineering, 4(7), 50 (2019). DOI: 10.26730/2618-7434-2019-4-50-66

5. A.V. Katsubin, A.A. Fedotov, Journal of Mining and Geotechnical Engineering, 3(6), 60 (2019). DOI: 10.26730/2618-7434-2019-3-60-75

6. O. Litvin, M. Gasanov, S. Zhironkin, M, Tyulenev, Int. J. Of Mining and Mineral Eng. (to be published)

7. N.G. Dombrovsky, Excavators (Mechanical Engineering, Moscow, 1969)

8. M. Tyulenev, S. Markov, M. Cehlar, S. Zhironkin, M. Gasanov, Acta Montanistica Slovaca, 23(4), 368 (2018)

9. S. Markov, J. Janočko, M. Tyulenev, Y. Litvin, E3S Web Conf., 105, 01021 (2019)

10. M.A. Tyulenev, S.O. Markov, M.A. Gasanov, S.A. Zhironkin, Geotechnical and Geological Engineering, 36(5), 2789 (2018)

11. T. Gvozdkova, S. Markov, N. Demirel, S. Anyona, E3S Web Conf., 21, 01024 (2017)

12. H. Liu, M. Kearney, M. Forbes, IFAC-PapersOnLine, 50(1), 12477 (2017)

13. S. Markov, M. Tyulenev, O. Litvin, E. Tyuleneva, E3S Web Conf., 15, 01011, (2017)

14. I.V. Zenkov, B.N. Nefedov, M.A. Ragozina, E.V. Loginova, Ugol', 6, 42 (2018)

15. T. Gvozdkova, E. Kuznetsov, A. Rudakova, S. Markov, E3S Web Conf., 15, 01008, (2017)

16. R. Khayrullin, MATEC Web of Conferences 86, 04049 (2016)

17. A. Jessett, Canadian Mining J. 137(7), 30 (2016) 
18. Y.V. Romashkin, V.V. Sidorov, IOP Conference Series: Earth and Environmental Science 378(1), 012097 (2019)

19. T.A. Tsymbalyuk, N.A. Nemova, IOP Conference Series: Earth and Environmental Science 262(1), 012079 (2018)

20. M.I. Shchadov, Ugol' 11, 25 (1985)

21. M.M. Bereznyak, A.V. Kalinin, V.G. Pronoza, Soviet Mining Science 6(6), 638 (1970)

22. S.M. Miliy, Journal of Mining and Geotechnical Engineering 1(8), 45 (2020) doi: 10.26730/2618-7434-2020-1-45-73

23. M. Cehlár, P. Rybár, J. Mihók, J. Engel, Journal of Mining and Geotechnical Engineering 1(8), 4 (2020) doi: 10.26730/2618-7434-2020-1-4-31

24. V.G. Pronoza, V.F. Voronkov, A.S. Nenashev, A.S. Tashkinov et al. Typical technological schemes of mining operations at coal open pit mines (Nedra, Moscow, 1982)

25. A.B. Palamarchuk, A.V. Stukan, T.N. Gvozdkova, Journal of Mining and Geotechnical Engineering 1(4), 50 (2019) doi: 10.26730/2618-7434-2019-1-50-68 